\title{
Explorando Registros Figurais: implicações para o desenvolvimento do pensamento geométrico
}

Exploring records figurais: implications for the development of thought geometric

\author{
Raimundo Luna Neres ${ }^{1}$ \\ José Carlos Miguel $^{2}$ \\ Camila Everton Guterres ${ }^{3}$
}

\section{Resumo}

Neste artigo, apresentamos os resultados de um estudo sobre as produções de alunos de uma Universidade Particular, envolvendo representações de registros em regiões do plano. As atividades foram elaboradas à luz da teoria dos registros de representação semiótica (DUVAL,1995; 2007) e requeriam do acadêmico o estabelecimento de tratamento e conversão entre registros figurais. As tarefas foram aplicadas em três etapas: a primeira e a segunda etapas constaram da construção de regiões delimitadas por quadriláteros e, a partir da escolha de um dos quadriláteros, em particular, um retângulo, construir subfiguras e encontrar algoritmos que permitissem calcular suas respectivas áreas. Na terceira etapa, foram propostas situações relacionando conversão e tratamento de registros figurais, com o objetivo de investigar possíveis obstáculos dos alunos em trabalhar com registros figurais. Os resultados sinalizam a inconsistência de conceitos básicos de geometria plana e dificuldades de os acadêmicos operarem com conversão de figuras geométricas, assim como em encontrar os algoritmos que permitam calcular áreas das subfiguras construídas. Palavras chave: Construção de subfiguras; conversão de registros figurais; cálculo de áreas.

\section{Abstract}

In this paper, we showed results of a study about student essays at a private College, containing records presentations in planned regions. The activities were worked out under the theory of semioptics presentation records (DUVAL, 1995; 2007) and required from the students the treatment set as well as the conversion of figures records the tasks had three stages: the first and second stages were of limited regions by four-sided and from the choice of one the four-sided angles in particular, a rectangle to ramp up subfigures and find algorisms that would allow to calculate their respective areas. In the third stage situations were proposed relating conversion and figures records treatment in order for to investigate students possible obstacles to work with figures records. The results signal to inconsistency

\footnotetext{
${ }^{1}$ raimundolunaneres@gmail.com

2 jocarmi@terra.com.br

3 camilaeverton@live.com
} 
of plain geometry basic concepts and difficulties to deal with geometry figures conversion, as well as to find algorisms that allow them to calculate areas of built subfigures.

Keywords: Subfigures building; figures records conversation; areas calculating.

\section{Introdução}

Este artigo tem como objetivo analisar os dados de uma investigação empírica realizada com alunos do primeiro ano do Curso de Engenharia Ambiental de uma Universidade Particular de São Luís - Maranhão, em que o foco foi investigar possíveis dificuldades dos alunos em operar com registros figurais e verificar o desempenho escolar na aplicação de conversão e tratamento desses registros.

Usando a mudança entre registros de representação como uma habilidade básica, o professor não pode deixar de considerar as especificidades referentes aos diferentes tipos de registros e formas de trabalhar com a conversão entre registros de representação e o tratamento desses registros.

A mediação de conhecimentos, segundo Bruner (1978) permite ao professor ensinar determinadas estratégias de resolução aos seus alunos através de um problema, de modo a conduzi-los à aprendizagem que permita usá-las em outra situação, que possam estabelecer relações com as anteriores.

Normalmente, quando um aluno consegue resolver um problema, a satisfação do feito pode encorajá-lo a buscar novas experiências e levá-lo a descobrir novas resoluções.

Na resolução de problemas mais complexos a relação com o "ver" é tão importante como as capacidades relacionadas com o "fazer", verificando-se que na,

maioria das vezes os alunos selecionam as estratégias a utilizar na
resolução de um problema baseados no que "veem" no seu enunciado.
As resoluções visuais de problemas, que recorrem a registros figurais, ou a
propriedades geométricas nem sempre são fáceis de compreensão. O
início do recurso a objetos figurais poderá ser atribuído aos babilônios e
gregos, que desenvolveram problemas, sobretudo geométricos. No
entanto, nas últimas décadas aumentou bastante o interesse pelas provas
visuais, no caso das representações semióticas devem ser rigorosas, pois
podem conduzir a interpretações errôneas quando da aplicação da
conversão entre registros (VALE, 2015).

O foco principal de nosso objeto de estudo está centrado na teoria dos Registros de Representação Semiótica, buscando verificar como será o desempenho dos alunos, ao realizar conversões e tratamento de registros figurais.

Como acreditamos que só o sujeito consegue construir seu conhecimento e se desejamos participar de sua transformação escolar e cidadã segundo (LORENZATO, 2010) é preciso incentivar e permitir que eles se pronunciem em nossas aulas, haja vista que muitos dos obstáculos enfrentados por alunos na construção de seu saber têm origem na metodologia utilizada pelo professor.

O avanço no ensino e aprendizagem da matemática exige uma relação clara entre o desenvolvimento da compreensão dos conceitos matemáticos e o desenvolvimento das competências em trabalhar com situações problemas do cotidiano do aluno (VALE; PIMENTEL \& BARBOSA, 2015). Se conseguirmos que essas indicações se efetivem com mais consistências ao nível de desenvolvimento da matriz curricular em sala de aula, essas 
práticas poderão se tornar em um poderoso mecanismo para desenvolver conceitos matemáticos mais substantivos.

Na medição para construção do conhecimento matemático entre professor e aluno, com referência a resolução de problemas, devemos trabalhar na perspectiva do estudante ser ele mesmo o responsável pela tomada de decisão, não se prendendo somente a regras e modelos apresentados nos livros didáticos. Segundo Gontijo (2015) ao se propiciar aos alunos a oportunidade de construírem os seus próprios modelos (métodos) para a construção da resolução de um problema, estimula-o a criatividade, flexibilidade e originalidade.

Para atingir esse desiderato, os alunos deveriam delimitar numa folha de papel um quadrilátero e escolher um retângulo dentre os quadriláteros desenhados. A partir de esse retângulo construir subfiguras e descobrir o algoritmo que permitisse calcular suas respectivas áreas, assim como trabalhar com a conversão e tratamento entre esses registros figurais.

Para a execução da investigação, realizamos encontros com os alunos objetivando estudar e discutir alguns conceitos relativos a áreas de figuras planas e mediar atividades inerentes ao objeto de estudo.

Reconhecemos que as representações semióticas facilitam a aprendizagem matemática e contribui para o desenvolvimento cognitivo do sujeito. Quando nos apoiamos na compreensão dos conceitos ajudamos os alunos a estabelecer e perceber as conexões entre diferentes entes matemáticos, as ligações entre os conceitos,

\begin{abstract}
Matemáticos e as ideias provenientes da experiência, principalmente, num contexto de trabalho desenvolvido em sala de aula em que se priorize a utilização de uma variedade de tipos de representações matemáticas permite ao aluno expressar e comunicar as suas ideias, além disso, é mais uma ferramenta que ajuda a atingir a compreensão e apropriação de conceitos. Desse modo, afirmamos que as representações matemáticas podem ser encaradas como poderosas lentes através das quais podemos analisar a forma como os alunos exprimem o seu pensamento geométrico em relação ao objeto de estudo proposto (NOBRE; AMADO \& PONTE, 2015).
\end{abstract}

Na coleta de dados, utilizamos dois instrumentos: a observação participante que, segundo Fiorentini e Lorenzato (2009), é realizada junto aos comportamentos naturais dos sujeitos, quando estes estão conversando, ouvindo, trabalhando etc.; e a análise documental (HELDER, 2006), realizada com documentos originais escritos, aqueles que ainda não tiveram tratamento analítico ou de outra natureza.

Em nossa pesquisa, com relação à observação participante, foi realizada através das mediações dos pesquisadores com os sujeitos. Quanto à análise documental, foi realizada nas resoluções escritas dos problemas apresentados pelos alunos.

Ressaltamos que a investigação foi decorrente de nossas inquietações como professor de Matemática. Em geral, nos dois primeiros semestres dos cursos das engenharias, são ministradas disciplinas de vetores e geometria analítica, assim como de cálculo a uma variável. O que temos observado, ao longo dos anos de nossa prática de ensino, é que normalmente os alunos, ao cursarem essas disciplinas, apresentam limitações quanto ao domínio de alguns conteúdos básicos de geometria plana, como por exemplo, o cálculo de 
áreas. Daí a ideia de trabalhar alguns conceitos de geometria por meio da construção de figuras e subfiguras, com o objetivo de contribuir com a formação acadêmica desses alunos.

\section{Fundamentação Teórica}

A resolução de problemas, ao longo dos anos tem sido um propulsor fundamental de estímulo à renovação da matriz curricular e de práticas de ensino no Brasil e em muitos outros países. O movimento do problem solving arraigado de certo modo no Brasil tem sido uma base da construção do saber matemático e, principalmente, um instrumento de investigação em educação matemática.

A resolução de problemas mostra a sua importância em educação matemática,

Ao levantar novas questões e buscar novos contextos que ampliam o seu alcance e fazem dessa componente do saber, histórica e epistemologicamente, essencial para a construção do conhecimento matemático, ampliando as áreas de investigações, tais como: o uso de ferramentas tecnológicas e de representações digitais, o desafio instigante da Matemática, o design de problemas que potencializam a aprendizagem e compreensão das matemáticas, os desafio que os professores enfrentam ao trabalhar no dia a dia de sala de aula com resolução de problemas, a criatividade e a competição dentre muitos outros focos que podemos pesquisar (CARREIRA; BROCARDO, 2015, p. 1).

Depois de várias décadas de pesquisa e de publicações de resultados importantes sobre resolução de problemas, a capacidade dos alunos para resolver problemas, quer dentro da matemática, quer em outras áreas do conhecimento, ainda necessita de outras perspectivas, investimentos e desenvolvimento de novas matrizes curriculares para serem adotadas. "A capacidade dos alunos em resolver problemas ainda exige uma melhoria considerável, principalmente considerando a rápida evolução do mundo em que vivemos" (VALE; PIMENTEL; BARBOSA, 2015).

A descoberta de uma maneira de resolver um problema, em geral, deixa o aluno satisfeito e encorajado, na busca de novas experiências. Uma grande descoberta pode resolver um grande problema e sempre é possível descobrir novas resoluções. A priori, um problema pode ser modesto, mas se ele instigar a curiosidade do aluno, na busca pela solução, pode levá-lo a descobrir novas heurísticas. O gosto pelo trabalho mental pode deixar, por toda a vida, sua marca na mente e no caráter (POLYA, 2006).

Desenvolver nos alunos o sentido investigativo, intuitivo e indagador é um dos principais papéis do professor de matemática dos tempos modernos (AFONSO; FELIPE; BRANCO, 2014). Para que isso ocorra, é necessário ao professor elaborar bons exercícios que favoreçam o desenvolvimento cognitivo de seus alunos, tornando essa práxis corriqueira nas suas atividades de ensino, no dia a dia de labuta.

Considerando o problema como ponto de partida e orientação para a aprendizagem matemática, Allevato e Onuchic (2014) afirmam que a metodologia de ensino usando Resolução de Problema se constitui em um contexto bastante propício à construção de conhecimento, haja vista que coloca o aluno no centro do processo desenvolvido em sala de aula, tendo o professor o papel de mediador e organizador das atividades.

Usando a resolução de problemas como uma habilidade básica, o professor não pode deixar de considerar as especificidades referentes ao conteúdo de problemas, tipos e 
métodos de solução. Para Branca (1997), a questão é o que o professor deve eleger como essencial a ser ensinado em matéria de resolução de problema, assim como definir as técnicas que podem ser utilizadas.

O professor, ao ensinar determinadas heurísticas aos seus alunos, por meio de um problema, objetiva que esse aluno possa apreender os conhecimentos e usá-los em outro problema. Isto porque, segundo Silver e Smith (1997), o aluno precisa não apenas entender - que a heurística significa, mas também acreditar que as sugestões do professor, realmente, podem Ihe ser úteis. Em se conseguindo isso, é possível que os alunos consigam, com mais segurança, usar as heurísticas ensinadas.

Para descobrir relações existentes entre as áreas de determinadas figuras geométricas, torna-se imprescindível o conhecimento de simetria usada na resolução de problemas geométricos. A simetria pode ser considerada como a chave para abrir estruturas de vários problemas matemáticos. É possível que uma boa compreensão da simetria em matemática

Aprofunde a capacidade de discernimento em quase todos os ramos da matemática, assim como nas relações de suas diversas áreas. As figuras geométricas propiciam uma introdução natural à teoria dos grupos e à álgebra abstrata, como também em importantes aplicações dessa ciência. Enfim, a simetria pode fornecer valiosas contribuições em descobertas da aritmética, álgebra elementar e avançada (GOLDIN; MCCLINTOCK, 1997, p. 249-250).

Com base nesses pressupostos, apresentamos um recorte de uma pesquisa empírica realizada com uma turma do primeiro ano do Curso de Engenharia Ambiental de uma Universidade Particular de São Luís, no Estado do Maranhão-Brasil, cujas análises sobre tratamento e conversão de registros figurais estão apoiadas na Teoria dos Registros de Representação Semiótica de Duval.

O fenômeno da resolução de problemas exige a conversão entre registros de representação. Para efetuar a conversão, é necessário selecionar, no enunciado, os dados pertinentes para a resolução, isto é, os números indicados, os valores que thes são atribuídos lexicamente e organizar esses dados de maneira que a operação matemática a ser executada se torne evidente e consistente (DAMM, 2007).

Define-se,

Tratamento de registros de representação - como sendo as operaç̃̃es realizadas dentro do próprio registro em que ele foi enunciado e Conversão de uma representação em outra - como sendo a transformação de uma representação em outra representação, isto é, de um registro em outro registro, podendo conservar a totalidade ou apenas uma parte do registro dado como ponto de partida (DUVAL, 2007, p. 1617).

Na maioria das vezes, a visualização dos objetos pode estar relacionada ao fato de que o aluno não consegue explicitar o objeto através de representações semióticas. Essas dificuldades, em geral, prejudicam a compreensão da Matemática, haja vista que, quando isso ocorre, pode haver uma perda da compreensão já adquirida, como por exemplo, em geral, o aluno apresenta dificuldades para descrever o que representa determinados sólidos geométricos. 
Dessa forma, o acesso aos objetos matemáticos passa necessariamente por representações semióticas. Destarte, a sua compreensão pode estar condicionada à capacidade de permutação de registros. Os objetos estudados foram: conceitos, propriedades, estruturas e relações geométricas que podiam expressar diferentes situações para o ensino, levando em consideração as diferentes formas de representação de um mesmo objeto matemático. Os primeiros passos que se espera do aluno é a compreensão do que seriam essas representações geométricas tão essenciais ao funcionamento e ao desenvolvimento dos conhecimentos matemáticos. A resolução de problemas de geometria,

E a entrada na forma de raciocínio que essa resolução exige depende da tomada de consciência e da distinção das formas de apreensão do registo figural (figura). A apreensão operatória das figuras depende das modificações que a figura pode sofrer, como por exemplo, a transformação de uma figura em outra considerada sua imagem, ou a figura pode separar-se em partes que são subfiguras da figura dada inicialmente (DUVAL, 1995, p.78-79).

Em geral, as modificações de figuras, incialmente, são realizadas mentalmente, depois passam para o registro gráfico. Segundo (ALMOULOUD, 2007), o interesse de fraccionar uma figura, ou seu exame, a partir de partes elementares, está ligado à operação de reconfiguração intermediária, ou seja, a operação consiste em organizar uma ou várias subfiguras diferentes de uma figura dada em outra figura, de tal forma que as subfiguras encontradas possam ser reagrupadas, organizadas em outras figuras, obedecendo à figura de partida. Dessa forma, os problemas de geometria (DUVAL, 1983) apresentam uma grande originalidade em relação a muitas outras tarefas matemáticas que podemos propor aos alunos.

A ação didático-pedagógica desenvolvida deve exercer, então, o papel de elemento organizador ou de mediação do processo de aprendizagem do aluno. Desta forma, o interesse do docente é conduzir o estudante a dar forma ao modelo teórico que resulta de uma atividade que reproduz a dimensão da escola, haja vista que desenvolvendo um objetivo de ensino está, em última instância, representando uma determinada cultura e uma forma específica de fazer Matemática.

\section{Trajetória Metodológica}

Seguimos, de acordo com a natureza do objeto e dos objetivos do estudo, uma abordagem empírico-analítica que, de acordo com Fiorentini e Lorenzato (2012), se ocupa, dentre outros temas, de técnicas de ensino da matemática, de rendimento/desempenho/desenvolvimento/heurística e motivação do aluno em busca de novos saberes.

O trabalho foi realizado no primeiro semestre letivo de 2015 e desenvolvido em etapas. Os registros dos dados foram feitos com o auxílio de dois instrumentos: o diário de bordo e as construções dos alunos em papel A4. Participaram da pesquisa 30 alunos do primeiro ano do Curso de Engenharia Ambiental de uma Universidade Particular de São Luís Maranhão - Brasil. 
Para atender ao desiderato metodológico, inicialmente os alunos foram divididos em grupos e orientados a delimitar quadriláteros, em folhas de papel $A_{4}$. Em seguida, procuraram identificar um retângulo dentre os quadriláteros desenhados e, depois encontrar (determinar, descobrir) o algoritmo ou heurística que permitisse encontrar a área do retângulo selecionado. A partir do retângulo escolhido, os alunos deveriam construir outras subfiguras, iniciando com, por exemplo, um triângulo e descobrir o algoritmo que permitisse determinar a área desse triângulo, usando apenas os dados revelados na subfigura encontrada. Usando o mesmo procedimento, partindo do retângulo, cada grupo de alunos deveria encontrar outras subfiguras, tais como: losango, paralelogramo e trapézio. Depois, deveriam descobrir o algoritmo que permitisse encontrar suas respectivas áreas.

A análise do material foi desenvolvida por meio de recorte do conteúdo por subfiguras (análise temática categorial) e envolveu análise de registros de figuras planas, de subfiguras construídas, codificação (heurística e algoritmo para o cálculo de áreas respectivas), tratamento e conversão de registros figurais.

Finalizando a pesquisa, foram aplicadas atividades, com aporte na Teoria dos Registros Semióticos, com o objetivo de verificar a aprendizagem dos alunos.

\section{Apresentação dos Dados}

As atividades foram elaboradas objetivando explorar as potencialidades dos sujeitos da pesquisa e foram aplicadas em momentos distintos. Inicialmente, potencializando a construção de subfiguras geométricas e o desenvolvimento de algoritmos para calcular as áreas das subfiguras construídas. Com esse procedimento, era requerido do aluno o tratamento e a conversão, assim como o fenômeno da heterogeneidade da conversão entre representação de registros figurais.

Num primeiro momento, os alunos foram divididos em oito grupos compostos por quatro alunos cada, que denominamos de " $A, B, C, D, E, F, G$ e $H^{\prime \prime}$ e solicitamos que os alunos de cada grupo desenhassem quadriláteros, depois escolhemos, dentre os quadriláteros desenhados, um retângulo.

Em seguida, foi solicitado que os alunos dos grupos construíssem um retângulo quadriculado semelhante ao desenhado na fig. 1, de tal maneira que cada divisão tivesse dimensões iguais. Depois, deveriam marcar nesse retângulo os pontos $A, B, C, D, M, N, O, P$, Q e R, conforme fig.1.

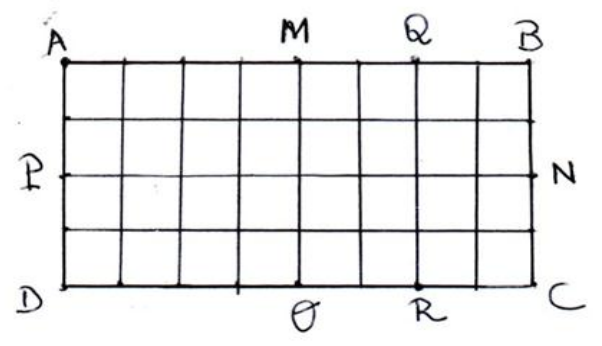

Figura 1: Retângulo quadriculado. 
A partir desse registro figural, requeremos dos alunos de cada grupo:

Encontrar o algoritmo para calcular a área do retângulo ABCD, (fig. 1);

Dividir o retângulo em duas partes iguais, traçando uma diagonal ligando o vértice $D$ ao $B$, e encontrar o algoritmo para calcular a área da subfigura delimitada pelos lados DB, $\mathrm{BC}$ e $\mathrm{CD}$, respectivamente;

Ligar os pontos médios do retângulo quadriculado, i.e., ligando os pontos $\mathrm{M}$ ao $\mathrm{N}$; $\mathrm{N}$ ao O; O ao P; P ao M e encontrar o algoritmo para calcular a área da subfigura construída;

Ligar o ponto $Q$ ao $C$ e encontrar o algoritmo para calcular a área da subfigura delimitada pelos lados AQ, QC, CD e DA.

\section{Análise dos Dados}

A totalidade dos alunos dos grupos conseguiu desenhar os quadriláteros solicitados pelo pesquisador, assim como desenhar um retângulo e quadriculá-lo nas dimensões solicitadas, embora se tenha observado que alguns alunos tiveram melhor desenvoltura do que outros no manuseio com lápis e papel.

As produções que apresentamos dos alunos dos grupos em estudo foi escolhida aleatoriamente. Convém salientar, que alguns alunos dos grupos A, C e F apresentaram muitas dificuldades para construir (encontrar) os algoritmos para calcular as áreas das subfiguras construídas. Mesmo após várias intervenções, mediações, dos pesquisadores fornecendo subsídios para que eles conseguissem montar as subfiguras solicitadas e encontrar os algoritmos respectivos, entretanto muito demonstraram competências ao trabalhar com representação de registros figurais.

Pudemos também observar que a maioria dos alunos estavam acostumado a aplicar diretamente a fórmula (algoritmo) aprendido no ensino fundamental para calcular áreas de figuras planas, desconheciam totalmente outra estratégia de como proceder para encontrar outro caminho que levasse ao mesmo algoritmo que permite também calcular áreas de figuras planas. A seguir apresentamos algumas considerações para o item a (fig. 2) apresentadas pelos grupos B, D, E e H. Deixamos de apresentar as produções dos outros grupos porque procederam de modo análogo.

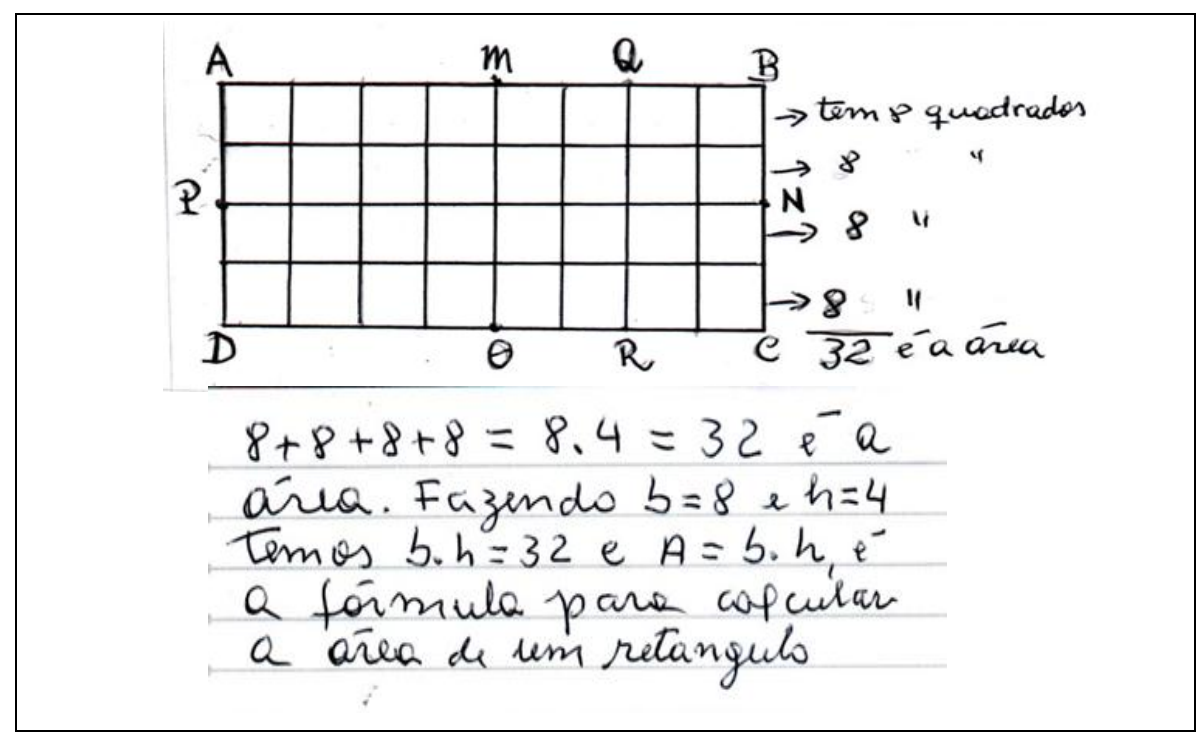

Figura 2: Algoritmo para calcular a área de um retângulo 
A seguir, na fig. 3, apresentamos as considerações para o item b, produzidas pelos alunos dos grupos A, C, D e E, os demais grupos procederam de modo semelhante a estes, entretanto salientamos que os grupos $B$ e $G$ foram os que apresentaram menor desenvoltura na construção de suas resoluções ao problema proposto.

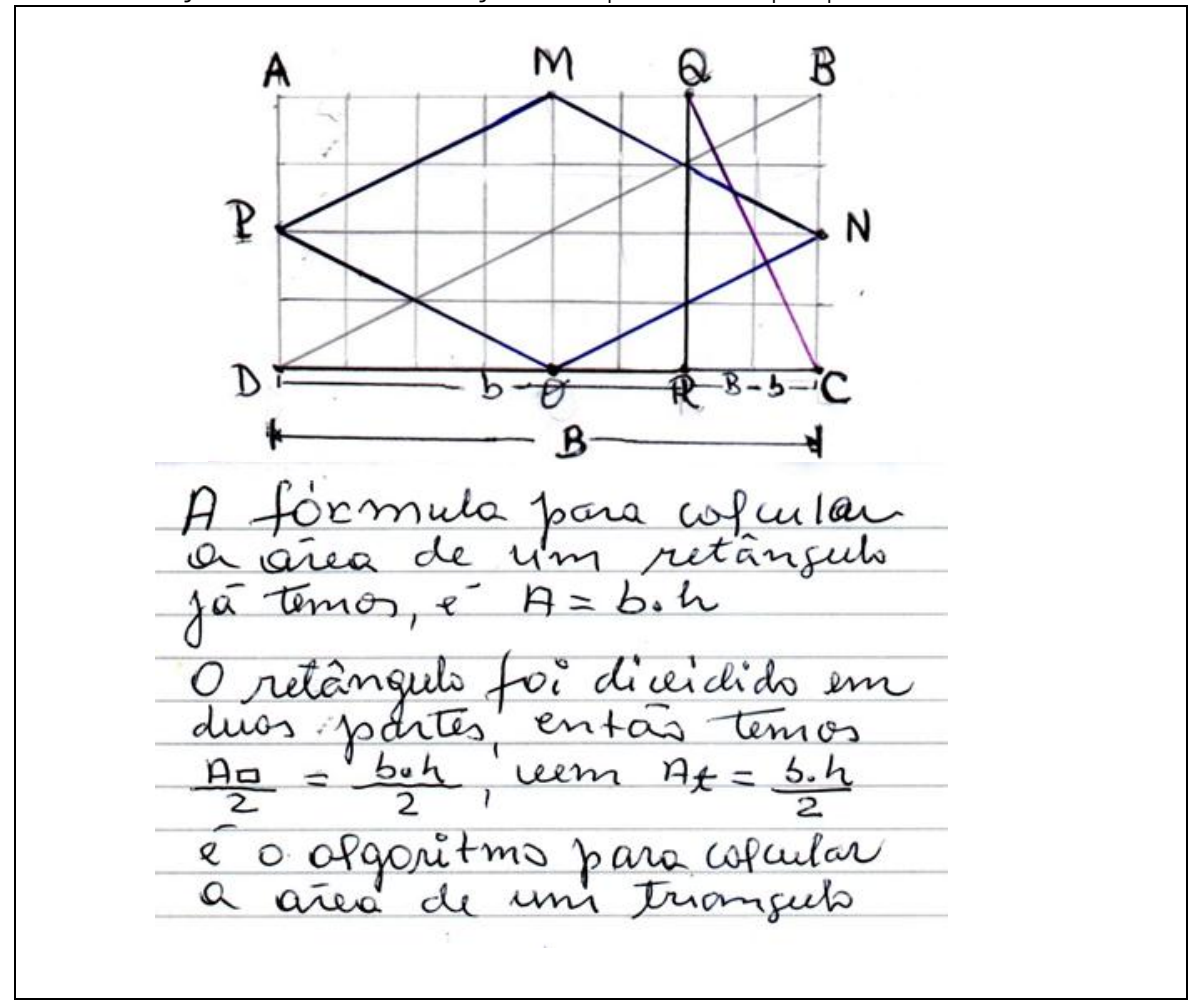

Figura 3: Algoritmo para calcular a área de um triângulo

A seguir na fig. 4, apresentamos a resolução construída pelos grupos A, B, C, D e G, para $\mathrm{O}$ item $\mathrm{C}$, tomando por base a fig.3. Os demais grupos também apresentaram resoluções semelhantes.

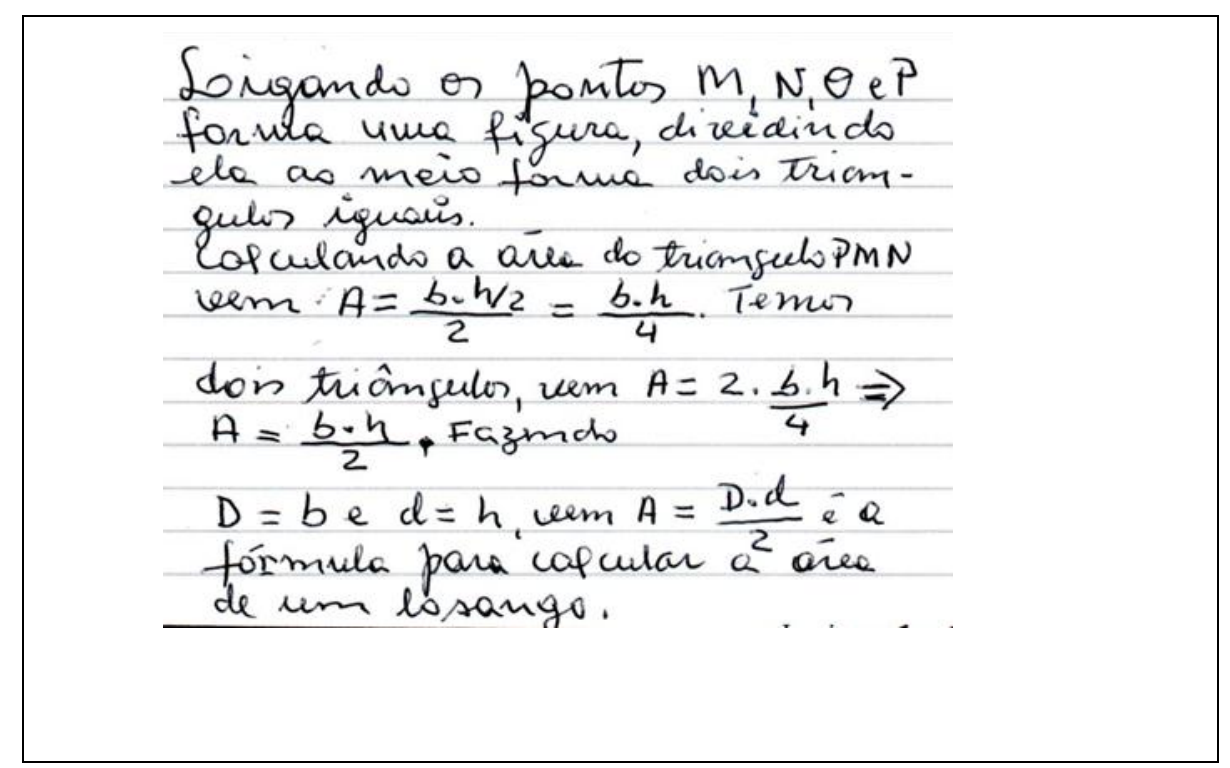

Figura 4: Algoritmo para calcular a área de um losango 
A seguir, na fig. 5, apresentamos a resolução construída pelos grupos B, D, E e F para item $d$, tomando, ainda, por base a fig.3. As demais resoluções apresentadas foram idênticas a estas.

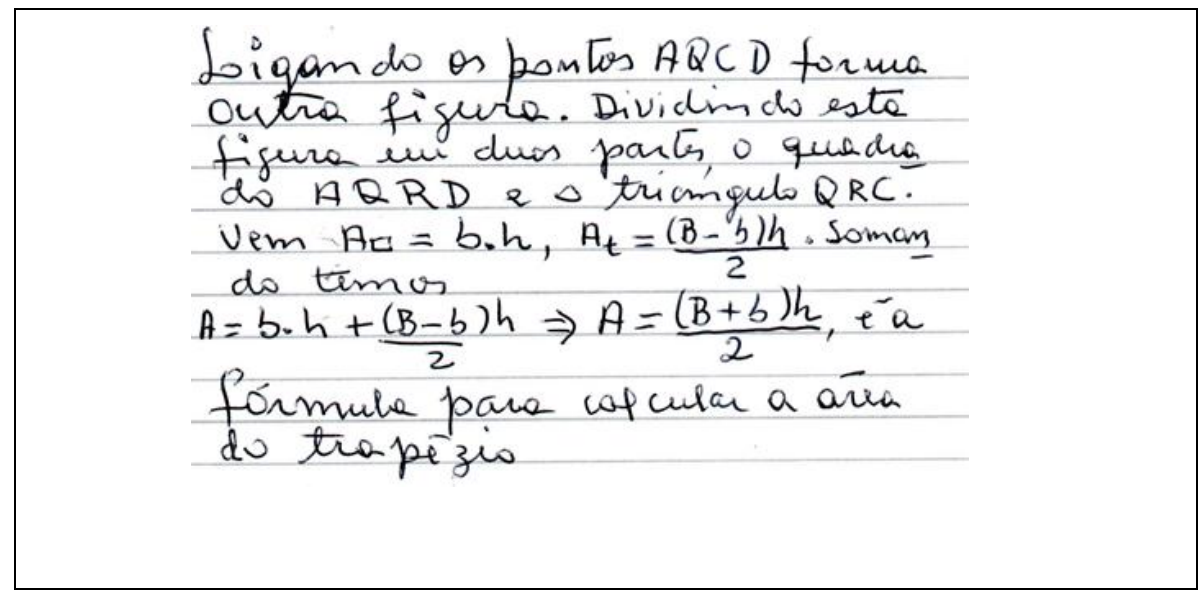

Figura 5: Algoritmo para calcular a área de um trapézio

Em seguida, aplicamos uma atividade com o objetivo de verificar se os alunos saberiam aplicar as fórmulas (algoritmos) para o cálculo de algumas áreas que eles encontraram.

\section{Atividade 1:}

O retângulo da fig. 6 tem área igual a $216 \mathrm{~cm}^{2}$, sendo $B$ o ponto médio do lado $A C$. Calcular a área da subfigura BCF e da subfigura BCEF.

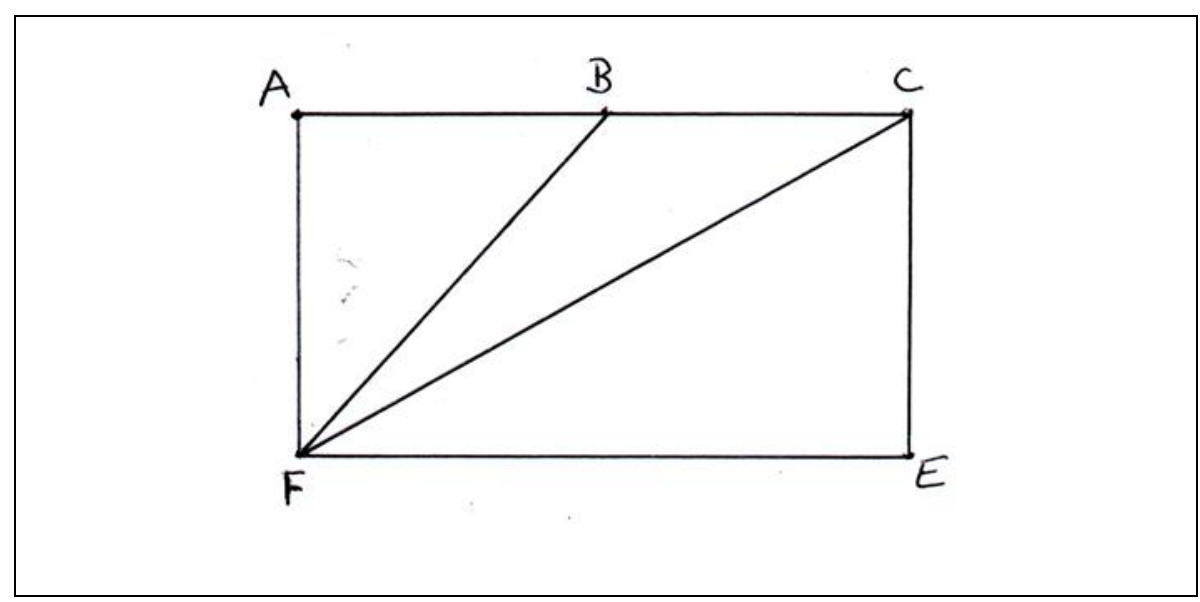

Figura 6: retângulo ACEF

Alguns alunos dos grupos A, C e D mediram os lados do retângulo e usaram o algoritmo encontrado por eles, para calcular as áreas solicitadas, sem levar em consideração os dados da hipótese do problema. Outros grupos tentaram atribuir valores por tentativa, mas não chegaram ao resultado correto. Apenas os alunos dos grupos $E, F$ e $G$ conseguiram encontrar uma resolução, embora houvesse intervenção do pesquisador, mediando as várias etapas da construção da resolução. 


\section{Atividade 2:}

Na fig. 7, apresentamos um retângulo cuja área é igual a $192 \mathrm{~cm}^{2}$, sendo B e D os pontos médios dos lados AC e CE, respectivamente. Calcular a área das subfiguras BDF e DEF, respectivamente.

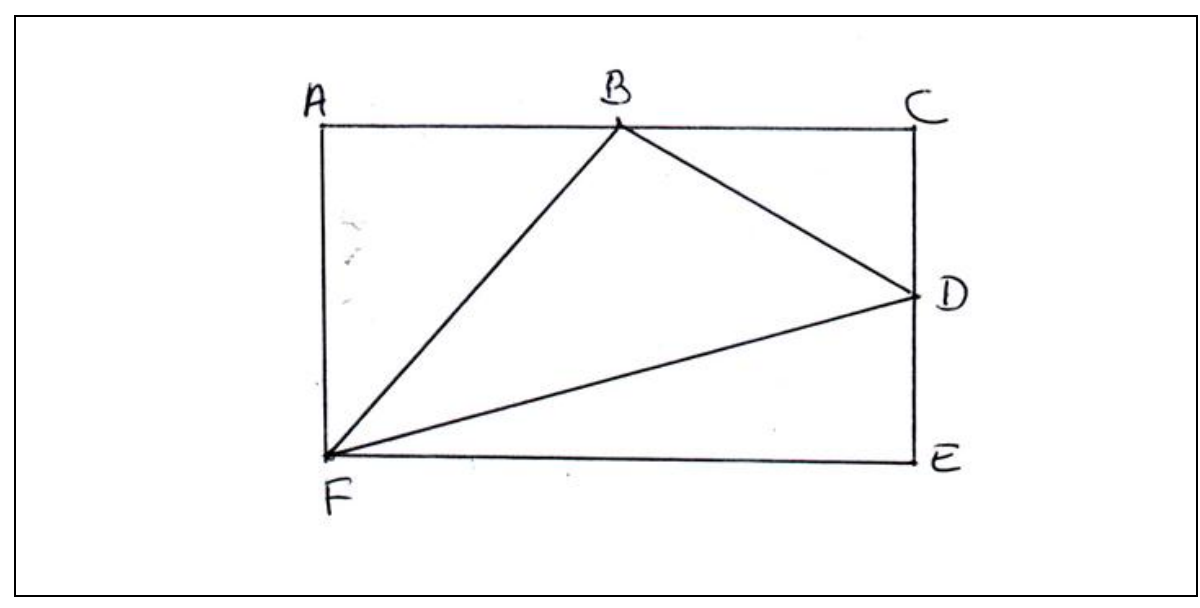

Figura 7: retângulo ACEF

As respostas construídas pelos alunos da maioria dos grupos foram semelhantes às dadas pelos alunos dos grupos A, C e D para o problema da primeira atividade, ou seja, não usaram os dados da hipótese do problema. Entretanto, após mediação dos pesquisadores os outros grupos conseguiram construir uma resolução corretamente.

\section{Considerações Finais}

Os resultados da pesquisa comprovaram que os alunos apresentaram muitas limitações em trabalhar com representações de registros figurais. No caso específico do nosso objeto de estudo, ficou evidenciado que a apreensão da aprendizagem geométrica não se restringe apenas ao tratamento de diferentes registros de representação semiótica, mas principalmente por não apropriação de conteúdos básicos de geometria plana.

Em geral, os alunos estão acostumados a receber algoritmos prontos para aplicar, de preferência, imediata em resolução de problemas. Quando se requer, em alguma atividade, questões que busquem o desenvolvimento cognitivo, poucos são aqueles que se saem bem.

Buratto (2006) fez um estudo reflexivo sobre o ensino-aprendizagem do conteúdo de áreas de figuras geométricas planas.

Buscava uma nova prática pedagógica, assim como a formação de conceitos geométricos, utilizando a Teoria dos Registros de Representação Semiótica. Observou que as dificuldades em trabalhar com os diferentes tipos de registros, na apreensão da aprendizagem da geometria, ocorreram muito mais em função de deficiências de conteúdo. Alguns alunos ainda desconheciam que a Matemática, para ser 
compreendida, não basta que ela seja ensinada apenas de modo lógico, depende, também, da habilidade do professor e do interesse do sujeito cognoscível. Esse binômio favorece a aprendizagem. (BURATTO, 2006, p.49-52).

O ensino da geometria deve perpassar o uso de técnicas e aplicação de fórmulas; deve estimular a busca de novas heurísticas de resolução de problemas, contribuindo para o desenvolvimento do raciocínio do aluno.

Por certo, as representações matemáticas dos estudantes diferem das representações de seus professores. De igual modo, as representações entre os docentes também diferem bastante, relacionando-se intrinsecamente com as suas concepções de Matemática e de sociedade. De forma sintética, podemos dizer que ao se defrontarem com situações novas os alunos usam o conhecimento desenvolvido através da experiência adquirida em situações anteriores, buscando adaptá-lo à situação nova.

Em consonância com os resultados obtidos, este estudo revela a importância do estudo da geometria desde os primeiros anos do ensino da matemática, propondo atividades com abordagens conceituais, aspectos procedimentais e, principalmente, buscando aguçar a curiosidade do aluno em processos de descobertas de novas heurísticas, tanto na resolução de problemas escolares quanto de seu cotidiano.

\section{Referências}

AFONSO, Paulo; FELIPE, José e BRANCO, Ana Rita. Quadrados Mágicos envolvendo números figurados. Revista Educação e Matemática, Lisboa-Pt, ASPRINT, Apolinário Silva, Unipessoal Lda, v.1, n. 129, p. 39-42, 2014.

ALLEVATO, Norma S. G; ONUCHIC, Lourdes de la R. Ensino - Aprendizagem - Avaliação de Matemática: por que Através da Resolução de Problemas. In: ONUCHIC, Lourdes de la R; ALLEVATO, Norma S. G; et al. (Orgs.). Resolução de problemas: teoria e prática. Jundiaí/SP: Paco Editorial, 2014.

ALMOULOUD, S. Ag. Registros de Representação Semiótica e Compreensão de Conceitos Geométricos. In: MACHADO, S. D. A (Org.). Aprendizagem em Matemática: registros de representação semiótica. Campinas/SP: Papirus, 2007.

ANDRÉ, Marli. Etnografia da prática escolar. São Paulo: Papirus, 1995.

BRANCA, Nicholas A. Resolução de problemas como meta, processo e habilidade básica. In: KRULIK, S e REYS, Robert E. (Orgs.). A resolução de problemas na Matemática Escolar. Tradução: Hygino H. Domingues e Olga Corbo. São Paulo: Atual, 1997.

BRUNER, J. S. O processo da educação. São Paulo: Nacional, 1978.

BURATTO, Ivone Catarina Freitas. Representação semiótica no ensino da geometria: uma alternativa metodológica na formação de professores. 2006. 142 f. Dissertação (Mestrado em Educação Científica e Tecnológica) - Universidade Federal de Santa Catarina, Florianópolis, 2006.

CARREIRA, S.; BROCARDO, J. Resolução de problemas. Quadrante - Revista de Investigação em Educação Matemática. Lisboa/Portugal, v. XXIV, n. 2, p. 1-4, 2015. 
DAMM, R. F. Representação, Compreensão e resolução de problemas aditivos. In: MACHADO S. D. A. (Org.). Aprendizagem em matemática: registros de representação semiótica. $3^{\text {a }}$ ed. Campinas/SP: Papirus, 2007.

DUVAL, R. Registro de representação semiótica e funcionamento cognitivo da compreensão em matemática. In: MACHADO S. D. A. (Org.). Aprendizagem em matemática: registros de representação semiótica. Campinas/SP: Papirus, 2007.

Sémiosis et pensée humaine: registres sémiotiques et apprentissages intellectuels. Suisse: Peter Lang,1995.

Registres de Représentation sémiotique et Fonctionnement cognitif de la Pensée. In: Duval, R (Org.). Annales de Didactique et de Sciences Cognitives. Strasbourg: ULP, v. 5, p. 37-65, 1993.

FIORENTINI, D.; LORENZATO, S. Investigações em educação matemática: percursos teóricos e metodológicos. 3. ed. rev. Campinas: Autores Associados, 2009.

. Investigações em educação matemática: percursos teóricos e metodológicos. Campinas/SP: Autores Associados, 2012.

GOLDIN, Geraldo A. e MCCLINTOCK, C. Edwin. O tema da simetria na resolução de problemas. In: KRULIK, S e REYS, Robert E. (Orgs.). A resolução de problemas na Matemática Escolar. Tradução: Hygino H. Domingues e Olga Corbo. São Paulo: Atual, 1997.

GONTIJO, C. H. Técnicas de criatividade para estimular o pensamento matemático. Educação e Matemática - Revista da Associação de Professores de Matemática, Lisboa/Portugal, n. 135, nov/dez, 2015.

HELDER, R. R. Como fazer análise documental. Porto: Universidade de Algarve, 2006.

LORENZATO, S. Para aprender matemática. $3^{a}$ ed. Ver. Campinas, SP: Autores Associados, 2010.

NOBRE, Sandra.; AMADO, Nélia.; PONTE, João Pedro da. A resolução de problemas com a folha de cálculo na aprendizagem de métodos formais algébricos. Quadrante - Revista de Investigação em Educação Matemática. Lisboa/Portugal, v. XXIV, n. 2, p. 85-109, 2015.

POLYA, George. A arte de resolver problemas. Tradução de Heitor Lisboa de Araújo. Rio de Janeiro: Interciência, 2006.

SILVER, Edward A. e SMITH, J. Philip. Imagine um problema correlato. In: KRULIK, S.; REYS, Robert E. (Orgs.). A resolução de problemas na Matemática Escolar. Tradução de Hygino H. Domingues e Olga Corbo. São Paulo: Atual, 1999.

VALE, Isabel.; PIMENTEL, Teresa.; BARBOSA, Ana. Ensinar matemática com resolução de problemas. Quadrante - Revista de investigação em Educação Matemática, Lisboa/Portugal, v. XXIV, n.2, p. 40-60, 2015.

VALE, I. A criatividade nas (re)soluções visuais de problemas. Educação e Matemática Revista da Associação de Professores de Matemática, Lisboa/Portugal, n. 135, nov/dez, 2015. 